\title{
Glycemic control and the production of cytokines in diabetic patients with chronic periodontal disease
}

\author{
Controle glicêmico e produção de citocinas em pacientes diabéticos com doença periodontal crônica
}

\author{
Mayra Moura FRANCO' \\ Mariana Mader Miranda MORAES² \\ Poliana Mendes DUARTE ${ }^{3}$ \\ Marcelo Henrique NAPIMOGA ${ }^{4}$ \\ Bruno Braga BENATTI'
}

\section{ABSTRACT}

\section{Objective}

To evaluate the association of glycemic control and cytokine production in type 2 diabetic subjects with chronic periodontitis.

\section{Methods}

Gingival biopsies were performed in 40 patients, divided into four groups: systemically healthy subjects without periodontal disease (S); systemically healthy patients with chronic periodontitis (P); patients with well-controlled type 2 diabetes mellitus (DM) with chronic periodontitis (C); poorly controlled type 2 diabetes mellitus with chronic periodontitis (D). The production of interleukin (IL) $-4,-6,-10,-17$ and interferon (IFN) $-\gamma$ was quantified by ELISA.

\section{Results}

The production of IL-4, IL-10, IL-17 and INF- $\gamma$ was higher on group $D$ when compared to other groups $(p<0.05)$, which in turn were similar $(p$ $\geq 0.05$ ). In addition, there was no difference in the production of IL-6 in any of the evaluated groups ( $p \geq 0.05)$.

\section{Conclusion}

Were observed significantly elevated levels of pro-inflammatory and anti-inflammatory cytokines in patients with poorly controlled type 2 diabetes and chronic periodontitis, demonstrating that glycemic control may be associated to the immune inflammatory response of sites with chronic periodontitis.

Indexing terms: Chronic periodontitis. Cytokines. Diabetes Mellitus. Inflammation.

\section{RESUMO}

\section{Objetivo}

Avaliar a associação do controle glicêmico e a produção de citocinas em indivíduos diabéticos tipo 2 com doença periodontal crônica.

\section{Métodos}

Foram realizadas biópsias gengivais de 40 pacientes, distribuídos nos seguintes grupos: sistemicamente saudáveis sem doença periodontal (S); pacientes sistemicamente saudáveis com periodontite crônica (P); pacientes com diabetes mellitus (DM) tipo 2 controlado com periodontite crônica (C); pacientes com diabetes mellitus tipo 2 não controlado com periodontite crônica (D). Foram quantificadas através de ELISA, a produção das interleucinas (IL) $-4,-6,-10,-17$ e interferon (IFN) $-\gamma$.

\section{Resultados}

A produção de IL-4, IL-10, IL-17 e INF- $\gamma$ foi maior no grupo D quando comparada aos demais grupos ( $p<0.05$ ), que por sua vez foram similares entre si $(p \geq 0.05)$. Além disso, não houve diferença na produção de IL-6 em nenhum dos grupos avaliados $(p \geq 0.05)$.

\section{Conclusão}

Foram observados níveis significativamente elevados de citocinas pró-inflamatórias e anti-inflamatórias nos pacientes com diabetes mellitus tipo 2 não controlado e com periodontite crônica, demonstrando que o controle glicêmico pode estar associado com a resposta imunoinflamatória de sítios com periodontite crônica.

Termos de indexação: Periodontite crônica. Citocinas. Diabetes mellitus. Inflamação.

\footnotetext{
${ }^{1}$ Universidade Federal do Maranhão, Programa de Pós-Graduação em Odontologia. Campus do Bacanga. Av. dos Portugueses, s/n., 65085-580, São Luís, MA, Brasil. Correspondência para / Correspondence to: BB BENATTI. Email: <bbbenatti@gmail.com>.

${ }^{2}$ Universidade Federal do Maranhão, Faculdade de Odontologia. Campus do Bacanga. São Luís, MA, Brasil.

${ }^{3}$ Universidade de Guarulhos, Departamento de Periodontia. Guarulhos, SP, Brasil.

${ }^{4}$ Instituto e Centro de Pesquisa São Leopoldo Mandic, Laboratório de Imunologia e Biologia Molecular. Campinas, SP, Brasil.
} 


\section{INTRODUCTION}

Periodontal disease is considered a chronic infectious inflammatory disease characterized by intense leukocyte infiltration in the periodontal tissue resulting in secretion of various cytokines that lead to deleterious inflammatory processes and destruction of the periodontal tissue and alveolar bone ${ }^{1}$. Despite the fact that the majority of cases are well controlled by conventional periodontal therapy, some cases are still a therapeutic challenge particularly because we do not know how some mild forms of periodontal disease evolve into more severe forms ${ }^{2}$.

Diabetes Mellitus is a metabolic disease characterized by hyperglycemia due to deficient insulin production type 1 or type 2 , that is preceded by systemic inflammation, leading to reduced pancreatic $\beta$-cell function, apoptosis and insulin resistence ${ }^{3}$, the latter being more prevalent in adults. The interrelationship between periodontal disease and diabetes mellitus (DM) has been investigated and studies have shown that the prevalence, progression and severity of periodontal diseases is higher in diabetic individuals than in nondiabetic ones ${ }^{4-6}$.

The relationship between the mechanism of DM and chronic periodontitis has been described as bidirectional ${ }^{3}$, in which DM negatively affects the periodontal condition and periodontal disease negatively influencing glycemic control, increasing the risk of complications in diabetic patients? Other studies have analyzed glycemic control and periodontal disease $^{8-11}$ and they have found a positive relationship between poorly controlled type $2 \mathrm{DM}$ and the severity of periodontal disease ${ }^{9,12}$. However, the mechanisms that may lead to more severe periodontitis in individuals with poorly controlled diabetes in comparison with well-controlled diabetes remain unclear?.

Although the initial stages of periodontal disease appear to be associated with bacterial infection, especially to species that adhere and form subgingival biofilm, evidence shows that periodontitis has a multifactorial etiology, which is particularly related to the susceptibility of the host ${ }^{13}$. Indeed, studies have shown that the correlation between the number of bacteria in the periodontal tissue and the extent of periodontal disease does not occur in all cases ${ }^{14}$. Moreover, in many cases there seems to be a positive correlation between tissue destruction and recruitment of cells into the periodontium, predominantly lymphocytes, monocytes/macrophages, neutrophils and osteoclasts $^{15}$. This may indicate that, in addition to the presence of periodontal pathogens, an exacerbated immune response would be contributing to disease progression.

T-helper lymphocytes (Th), which are mediators of the immune response of the organism, may exhibit a Th1 pattern, producing for example, INF- $\gamma$ and IL-6, which consists predominantly of a cellular immune and pro-inflammatory response, or a Th2 pattern, such as IL-4 and IL-10, with antiinflammatory characteristics and a predominantly humoral immune response. Such polarization is determined by the production of typical cytokines and chemokines, and also specific cell types that determine the course and prognosis of various infectious, inflammatory or autoimmune diseases ${ }^{16}$.

On the other hand, Th17 cells are a distinct population of lymphocytes that are not related to Th1 and Th2 lymphocytes ${ }^{17}$. These are powerful pro-inflammatory cells that produce interleukin IL-17 and stimulate fibroblasts, endothelial cells, macrophages and epithelial cells to produce multiple pro-inflammatory mediators, including IL-1, IL-6, tumour necrosis factor (TNF)- $\alpha$ and chemokines, resulting in the induction of inflammation ${ }^{10}$. High levels of IL-17 have been detected in biopsies of patients with chronic periodontitis ${ }^{18}$ and the presence of Porphyromonas gingivalis was capable of stimulating $T$ lymphocytes to produce $\mathrm{IL}-17^{19}$. Although the involvement of IL-17 in periodontal disease has been shown ${ }^{18}$, its role in the induction or progression of this disease is still unclear. Therefore, it is important to understand the immune inflammatory mechanisms that are related to an increased susceptibility to periodontal disease in patients with type 2 diabetes in comparison with individuals without the disease $\mathrm{e}^{5,20}$.

Based on the data described above, we hypothesized that the more severe forms of periodontal disease have, at least partially, an exacerbated inflammatory response responsible for the destruction of tooth-supporting tissues and that glycemic control is associated to the inflammatory response at chronic periodontitis sites. Thus, the aim of this study was to assess the influence of glycemic control on the production of cytokines in type 2 diabetic patients with chronic periodontal disease.

\section{METHODS}

The patients were selected at the Periodontal Clinic of Guarulhos University. The study was approved by the Research Ethics Committee of UFMA (protocol N N 23115-005265/201089) and all the individuals included in the research received information about the study and signed a term of free and informed consent.

According to the inclusion criteria established, participated in the study subjects from both sexes and more than 30 year of age, dentate or partially edentulous patients (at least 15 natural teeth) with no evidence of systemic modifiers of periodontal disease such as osteoporosis and smoking. Periodontal examination was performed following the parameters: probing depth (PD), clinical attachment level (CAL), 
bleeding on probing (BoP) and visible plaque index (VPI) $)^{21}$. A single examiner performed all periodontal clinical exams.

Pregnant or lactating, individuals who had taken antibiotics, anti-inflammatory or hormonal therapy, and/or have received periodontal treatment in the last six months prior to surgery were excluded from the sample. In subjects diagnosed with chronic periodontal disease (more than 30\% of the sites with PD and CAL $\geq 4 \mathrm{~mm}$ and presence of BoP), biopsies were collected from sites with the indication for surgical periodontal therapy (PD $\geq 6 \mathrm{~mm})$. In healthy patients (no sites with CAL $>3 \mathrm{~mm}$ and $<20 \%$ of sites presenting BoP), the biopsies were collected from sites with no clinical signs of inflammation, indicated for gingivoplasty due to esthetical reasons. In diabetic patients, glycemic control was determined by glycosylated haemoglobin levels ( $\mathrm{HbA} 1 \mathrm{c})$, measured by high-performance liquid chromatography, were expressed as a percentage. Subjects who had $\mathrm{HbA} 1 \mathrm{c}$ values $>8 \%$ were assigned to the poorly controlled group, whereas subjects who presented $\mathrm{HbA} 1 \mathrm{c}$ levels $\leq 8 \%$ were assigned to the wellcontrolled group 8,11

The study included 40 subjects divided in the following groups:

Group S ( $n=10)$ : Systemically and periodontally healthy subjects with no sites of CAL measurements $>3 \mathrm{~mm}$ and $<20 \%$ of sites presenting BoP;

Group $P(n=10)$ : Subjects were diagnosed with generalized chronic periodontitis, with more than $30 \%$ of sites with $C A L>4 \mathrm{~mm}$ and presence of BoP;

Group C ( $n=10)$ : well-controlled diabetic subjects, diagnosed with chronic periodontitis, according to the abovedescribed criteria, and $\mathrm{HbA} 1 \mathrm{c}$ levels $\leq 8 \%$;

Group D ( $n=10)$ : poorly controlled diabetic subjects, diagnosed with chronic periodontitis, according to the abovedescribed criteria, and $\mathrm{HbA} 1 \mathrm{c}$ levels $>8 \%$.

The biopsies were collected on the most representative area of the inflammatory process and stored in $500 \mu \mathrm{L}$ of specific buffer for this purpose (protease inhibitor cocktail SIGMA ${ }^{\circledR}$ ). Specimens were macerated (IKA ${ }^{\circledR}$ T10 Basic; UltraTurrax ${ }^{\circledR}$ ), followed by centrifugation on $4^{\circ} \mathrm{C}$, for $10 \mathrm{~min}$ and 12000 rpm (Centrifuge $5417^{\circledR}$ ) and the supernatant frozen at $-70^{\circ} \mathrm{C}$ until the ELISA (Enzyme-Linked Immunosorbent Assay) was performed. Wells were incubated overnight on $4^{\circ} \mathrm{C}$ with $100 \mu \mathrm{L}$ well of trapping antibodies (eBioscience ${ }^{\circledR}-$ USA) against human cytokines (IL-4, IL-6, IL-10, IL-17 and INF- $\gamma$ ).

The following day, the plates were washed with PBS Tween, blocked with BSA 1\% diluted in PBS, to prevent nonspecific bindings and incubated for 2 hours at $37^{\circ} \mathrm{C}$. After blocking, rinsed one more time, and the standard curves at various dilutions or samples (in triplicate) were added and incubated at $4^{\circ} \mathrm{C}$ for $24 \mathrm{~h}$. The plates were washed three times with PBS Tween and the biotinylated polyclonal antibodies against human cytokines were diluted to the proportion that best fit each cytokine and then added to the plates $(100 \mu \mathrm{l} / \mathrm{well})$.

After incubation at room temperature for 1 hour, the plates were washed and $50 \mu /$ well of peroxidade-conjugated streptavidin diluted at 1:5000 was added. Next (fifteen minutes later) $50 \mu$ l of the color reagent (o-phenylenediamine$2 \mathrm{HCL} ; \mathrm{OPD}$, Sigma USA) was added and plates were kept in the dark at room temperature for 15-20 min. The absorbance was measured at $490 \mathrm{nM}$.

The analysis of data with normal distribution was achieved using the Analysis of Variance (ANOVA) followed by the Tukey test for the clinical parameters and cytokine levels. The Student t-test was used to compare the glycemic control between well-controlled and poorly controlled diabetic patients. Statistically significant differences were considered when $\mathrm{p}<0.05^{(*)}$.

\section{RESULTS}

It is possible to observe in Table 1 that the clinical parameters were lower in healthy subjects (group S) when compared to all the other groups $(p<0.05)$. In addition, poorly controlled diabetic patients showed a higher VPI value when compared to the other groups $(p<0.05)$, and a higher $\mathrm{PD}$ value when compared to non-diabetic patients $(p<0.05)$.

Table 1. Demographic characteristics of the studied population and clinical parameters of the selected teeth for gingival biopsies $($ mean $\pm S D)$

\begin{tabular}{|c|c|c|c|c|}
\hline & $\begin{array}{l}\text { Group } S \\
(n=10)\end{array}$ & $\begin{array}{l}\text { Group } P \\
(n=10)\end{array}$ & $\begin{array}{l}\text { Group C } \\
(n=10)\end{array}$ & $\begin{array}{l}\text { Group D } \\
(n=10)\end{array}$ \\
\hline Age & $42.2 \pm 6.3$ & $49.0 \pm 5.8$ & $47.1 \pm 6.8$ & $48.3 \pm 9.1$ \\
\hline $\mathrm{M} / \mathrm{F}$ & 5/mai & 5/mai & 5/mai & 5/mai \\
\hline HbA1c (\%) & - & - & $7.2 \pm 0.7 *$ & $11.1 \pm 2.3$ \\
\hline \multicolumn{5}{|l|}{ VPI (\%) } \\
\hline full-mouth & $\begin{array}{c}12.2 \pm \\
8.2^{\mathrm{a}}\end{array}$ & $\begin{array}{c}60.0 \pm \\
12.3^{b}\end{array}$ & $\begin{array}{c}60.0 \pm \\
13.3^{b}\end{array}$ & $\begin{array}{c}75.5 \pm \\
11.1^{c}\end{array}$ \\
\hline sampledteeth & $5.2 \pm 2.2^{a}$ & $\begin{array}{l}63.0 \pm \\
24.0^{b}\end{array}$ & $\begin{array}{l}65.0 \pm \\
32.0^{b}\end{array}$ & $\begin{array}{c}80.0 \pm \\
30.0^{c}\end{array}$ \\
\hline \multicolumn{5}{|l|}{$\mathrm{BoP}(\%)$} \\
\hline full-mouth & $3.4 \pm 4.1^{\mathrm{a}}$ & $\begin{array}{l}48.3 \pm \\
19.1^{b}\end{array}$ & $\begin{array}{l}46.2 \pm \\
22.6^{b}\end{array}$ & $\begin{array}{l}54.3 \pm \\
24.1^{b}\end{array}$ \\
\hline sampledteeth & $0^{a}$ & $66.7 \pm 4.0^{b}$ & $\begin{array}{l}73.0 \pm \\
29.0^{\mathrm{b}}\end{array}$ & $62.0 \pm 37.0^{b}$ \\
\hline \multicolumn{5}{|l|}{$\mathrm{PD}(\mathrm{mm})$} \\
\hline full-mouth & $2.1 \pm 0.5^{a}$ & $3.4 \pm 0.5^{b}$ & $3.8 \pm 0.7^{c}$ & $3.7 \pm 0.6^{c}$ \\
\hline $\begin{array}{l}\text { sampledteeth } \\
\text { CAL (mm) }\end{array}$ & $3.6 \pm 0.5^{a}$ & $6.6 \pm 0.6^{b}$ & $6.5 \pm 0.9^{b}$ & $6.9 \pm 0.6^{b}$ \\
\hline full-mouth & $2.3 \pm 0.4^{a}$ & $4.2 \pm 0.8^{b}$ & $4.3 \pm 1.0^{b}$ & $4.4 \pm 0.9^{b}$ \\
\hline sampledteeth & $2.3 \pm 0.2^{a}$ & $8.0 \pm 1.6^{b}$ & $7.7 \pm 1.3^{\mathrm{b}}$ & $8.4 \pm 2.5^{b}$ \\
\hline
\end{tabular}

Note: HbA1c: glycated haemoglobin; M: male; F: female; PI: plaque index; BoP: bleeding on probing; PD: probing depth; CAL: clinical attachment level. 
The quantitative production of cytokines, additionally demonstrated that the production of IL-4, IL-10, IL-17 and INF- $\gamma$ was higher in the patients with uncontrolled diabetes in comparison with the other groups $(p<0.05)$, which were in turn similar among them $(p \geq 0.05)$. In addition, no difference in the production of IL-6 was found in any of the assessed groups $(p \geq 0.05)$ (Figure 1).
IL-4
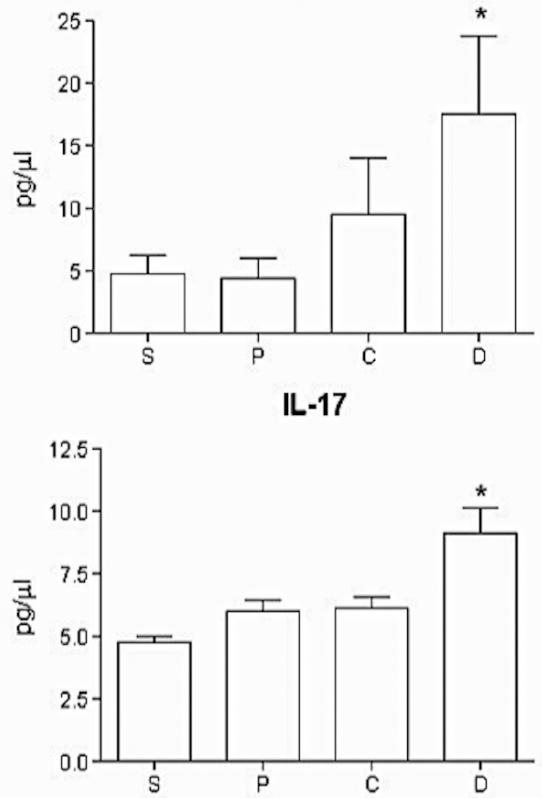

IL-10
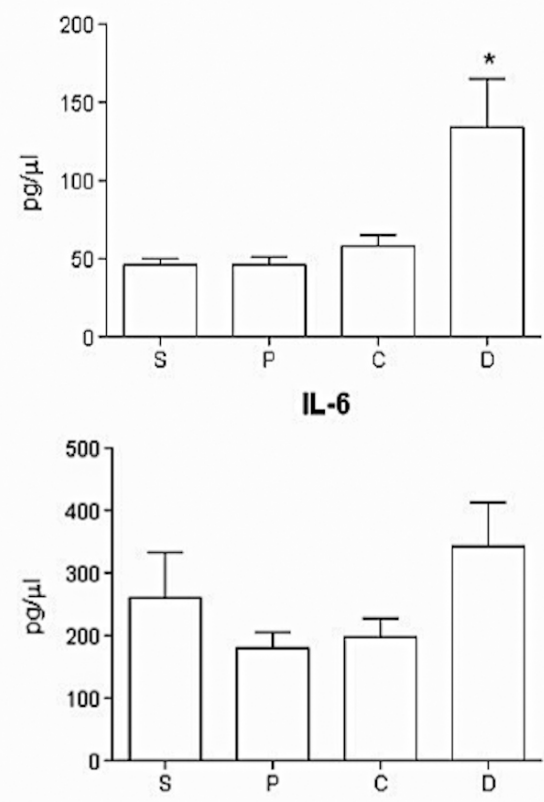

IFN-y

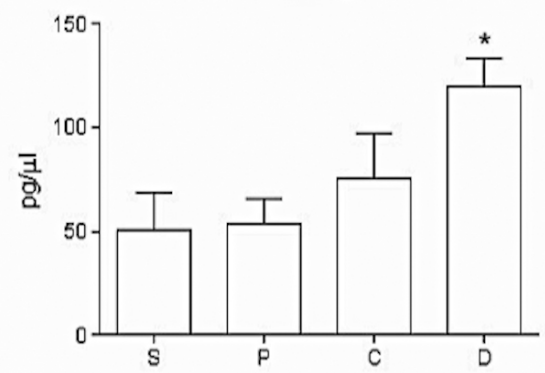

Figure 1. Quantitative expression of IL-4, IL-10, IL-17, IL-6 and IFN- $\gamma$ in healthy patients (S), in systemically healthy patients with chronic periodontal disease (P), patients with controlled diabetes and periodontal disease (C) and patients with uncontrolled diabetes and periodontal disease (D). Obtained by means of ELISA. Statistically significant $\left({ }^{\star}\right) \mathrm{p}<0.05$.

Different letters indicate statistically significant differences amongst experimental groups (ANOVA and Tukey test; $p<0.05)$ * Statistically significant differences between well-controlled and poorly controlled diabetic subjects (Student t-test; $\mathrm{p}<0.05$ ).

\section{DISCUSSION}

The study assessed the levels of pro- and antiinflammatory cytokines at sites with chronic periodontitis in patients with well-controlled and poorly controlled type 2 diabetes. In general, poorly controlled diabetes mellitus was associated to the production of cytokines, including IL-
17, in sites with chronic periodontal disease. Poor glycemic control has been associated to the severity of periodontal diseases ${ }^{7,9}$, so it is critical to understand the immune and inflammatory mechanisms that determine the increased susceptibility to periodontitis in patients with diabetes in comparison with individuals without diabetes ${ }^{20}$.

Some studies suggest that the relationship between pro-and anti-inflammatory mediators in the periodontal tissues of diabetic patients would be more prone to inflammation, which would lead to further destruction of the periodontal tissues ${ }^{11,21}$. Our study demonstrated in patients with type 2 diabetes mellitus and chronic periodontitis high levels of cytokines of both, 
Th1 pro-inflammatory cytokines, represented by IL-17 and IFN- $\gamma$, and Th2 anti-inflammatory cytokines, which consisted of IL-4 and IL-10. Górska et al. ${ }^{22}$ reported that cytokines play a crucial role in immune and inflammatory responses and the balance between them can determine the outcome of periodontal infection.

$\mathrm{IL}-17$ is a pro-inflammatory cytokine produced by Th17 cells, which stimulates the production of proinflammatory mediators ${ }^{23}$. Chronic periodontitis sites have shown increased levels of IL-17 in comparison with healthy periodontal tissues ${ }^{18,23}$ and periodontal pathogens can stimulate the production of IL-17 from T-cells ${ }^{19}$. In this study, the concentration of the cytokine IL-17 was higher in patients with poorly controlled diabetes, confirming the findings of Santos et al. ${ }^{11}$ and Ribeiro et al. ${ }^{20}$, which may indicate a possible role of Th17 pattern in periodontitis when correlated to $\mathrm{DM}^{8}$. This cytokine is associated with bone loss and with the production of other inflammatory markers such IL-6, increasing the severity of periodontal inflammation. In patients with poorly controlled diabetes, the high levels of $\mathrm{IL}-17$ may be responsible for bone resorption and the destruction of periodontal tissues ${ }^{11,20}$.

The quantitative expression of IFN- $\gamma$, produced by Th1 cells, was higher in the group of patients with poorly controlled diabetes and periodontal disease. IFN- $\gamma$ induces macrophage activation and the production of inflammatory mediators and it is also able to suppress the activity of Th2 cells ${ }^{22}$. Therefore, high levels of this cytokine have been related to periodontal disease progression ${ }^{22-23}$. Controversially, Ribeiro et al. ${ }^{20}$ and Santos et al. ${ }^{24}$ also found a higher expression of cytokines in patients with well-controlled diabetes and periodontal disease. According to Duarte et al. ${ }^{25}$, the levels of IFN- $\gamma$ are higher in inflamed sites than in non-inflamed sites, irrespective of the systemic condition, and this cytokine, despite having a role in the pathogenesis of periodontal disease, may not be directly involved in the mechanisms of periodontal bone destruction in diabetic patients.

Moreover, there was no statistically significant difference in the quantitative expression of IL-6 among the groups ( $p \geq 0.05$ ), a finding that was similar to the one found in the study of Duarte et al. ${ }^{8}$, in which the expressions of IL-6 and transforming growth factor (TGF)- $\beta$ did not reach any significant differences among the groups. Duarte et al. ${ }^{25}$ found higher levels of IL-6 in diabetic patients with chronic periodontitis and suggested that a high level of IL-6 may contribute to periodontal destruction in diabetic patients, which may be relevant for the modulation of periodontal disease in these patients.
In our study, the production of IL-4 and IL-10 was higher in the group of patients with poorly controlled diabetes, which is similar to the findings of Santos et al. ${ }^{11}$. Duarte et al. ${ }^{8}$ observed higher frequency of IL-4 in diabetic patients with chronic periodontitis, irrespective if it was well controlled or poorly controlled, when compared with healthy patients. IL-4 and IL-10 are involved with the Th2 anti-inflammatory immune response, which leads to a B-lymphocyte-dependent humoral response $\mathrm{e}^{22}$ and is related with a decrease in the activities of cytokines produced by cells of the Th1-pattern ${ }^{22-23}$. Takahashi et al. ${ }^{23}$ found a higher concentration of IL-10 in patients with chronic periodontitis when compared with healthy patients, suggesting that this cytokine be elevated in an effort to diminish the severity of inflammation in periodontal disease.

In the present study the pathways by which chronic hyperglycemia interferes in diabetic complications seem to be associated to the fomation of advanced glycation end products (AGE)s and/or the receptors (RAGES) that mediate their biological actions. The glycation process alters the structure of proteins (i.e. Extracellular matrix (ECM) proteins) leading to increased stiffness and resistance to proteolytic digestion. AGEs by accumulating within the various organs blood vessels, promotes several microvascular complications including neuropathies, ocular disease and atherosclerotic diseases ${ }^{26}$. The relation of hyperglycemia and the periodontal tissues have so far demonstrated conflicting results. In vitro, matrix glycation is able to modulate cell behavior to induce inflammation equivalent to that produced by incubation with $P$. gingivalis LPS. Such results were confirmed in vivo where AGE deposition and RAGE expression were considerably elevated in the later stages in animals with diabetes even in animals without diabetes but with periodontitis ${ }^{27}$. In humans, AGEs have been shown to be increasingly expressed in the periodontium of diabetic patients ${ }^{28}$, and also significantly associated with deterioration of periodontitis, whereas no other serum biochemical marker or bacterial occurrence showed a clear relationship with that condition ${ }^{29}$. However, other studies in humans have shown no extreme differences in periodontal clinical parameters, according to different glycemic contro ${ }^{30}$. Santos et al. ${ }^{24}$ observed no relationship between the severity and extension of periodontitis and the glycemic control in subjects well characterized as having advanced generalized chronic periodontitis. Differences in the type of DM, methods of analysis, and diagnosis of periodontal diseases may at least partially explain such controversial results. 
Overall, the present study showed that patients with type 2 diabetes mellitus and chronic periodontitis have high levels of cytokines of both patterns Th1 proinflammatory cytokines and Th2 anti-inflammatory cytokines. Górska et al. ${ }^{22}$ reported that cytokines play a crucial role in immune and inflammatory responses and the balance between them can determine the outcome of periodontal infection. The change in the pattern of inflammatory response can be explained as an attempt by the individual with diabetes and chronic periodontitis to balance or establish a pattern of Th immune response, which is not yet sufficiently clear. Thus, further studies to identify this specific etiology of severe chronic periodontitis in diabetic patients are needed.

\section{CONCLUSION}

Within the limitations of this study, significant higher levels of pro- and anti-inflammatory cytokines were observed in poorly controlled diabetic subjects with chronic periodontitis, demonstrating that glycemic control may influence the imunne inflammatory response in sites with chronic periodontal disease.

\section{Acknowledgements}

This study was supported by Maranhão State Research Foundation (FAPEMA, Maranhão, São Luís, Brazil, APP \# 1073/2009 and BIC \# 03730/10) and CNPq (\#303555/2013-0).

\section{Collaborators}

All authors made substantial contributions to all stages of conception and design of this study.

\section{REFERENCES}

1. Armitage GC. Development of a classification system for periodontal diseases and conditions. Ann Periodontol. 1999; 4(1):1-6. doi: 10.1902/annals. 1999.4.1.1

2. Gemmell E, Seymour GJ. Immunoregulatory control of Th1/ Th2 cytokine profiles in periodontal disease. Periodontol 2000. 2004;35(1):21-41. doi: 10.1111/j.0906-6713.2004.003557.x

3. Chapple IL, Genco R. Working group 2 of joint EFP/AAP workshop. Diabetes and periodontal diseases: consensus report of the Joint EFP/AAP Workshop on Periodontitis and Systemic Diseases. J Clin Periodontol. 2013;40(Suppl 14):S106-12. doi: 10.1111/jcpe.12077

4. Aspriello SD, Zizzi A, Tirabassi G, Buldreghini E, Biscotti T, Faloia $E$, et al. Diabetes mellitus-associated periodontitis: differences between type 1 and type 2 diabetes mellitus. J Periodontal Res. 2011;46(2):164-9. doi: 10.1111/j.1600-0765.2010.01324.x

5. Longo PL, Artese HP, Rabelo MS, Kawamoto D, Foz AM, Romito $\mathrm{GA}$, et al. Serum levels of inflammatory markers in type 2 diabetes patients with chronic periodontitis. J Appl Oral Sci. 2014;22(2):103-8. doi: 10.1590/1678-775720130540

6. Chee B, Park B, Bartold PM. Periodontitis and type II diabetes: a two-way relationship. Int J Evid Based Healthc. 2013;11(4):31729. doi: 10.1111/1744-1609.12038

7. Taylor GW, Borgnakke WS. Periodontal disease: associations with diabetes, glycemic control and complications. Oral Dis. 2008;14(3):191-203. doi: 10.1111/j.1601-0825.2008.01442.x

8. Duarte PM, Miranda TS, Lima JA, Dias Gonçalves TE, Santos VR, Bastos MF, et al. Expression of immune-inflammatory markers in sites of chronic periodontitis in patients with type 2 diabetes. J Periodontol. 2012;83(4):426-34. doi: 10.1902/jop.2011.110324

9. Costa FO, Miranda Cota LO, Pereira Lages EJ, Soares Dutra Oliveira AM, Dutra Oliveira PA, Cyrino RM et al. Progression of periodontitis and tooth loss associated with glycemic control in individuals undergoing periodontal maintenance therapy: a 5-year follow-up study. J Periodontol. 2013;84(5):595-605. doi: 10.1902/jop.2012.120255

10. Park $H$, Li Z, Yang $X O$, Chang $S H$, Nurieva R, Wang $Y H$, et al. A distinct lineage of CD4 T cells regulates tissue inflammation by producing interleukin 17. Nat Immunol. 2005;6(11):1133-41. doi: 10.1038/ni1261

11. Santos VR, Ribeiro FV, Lima JA, Napimoga MH, Bastos MF, Duarte PM. Cytokine levels in sites of chronic periodontitis of poorly controlled and well-controlled type 2 diabetic subjects. J Clin Periodontol. 2010;37(12):1049-58. doi: 10.1111/j.1600051X.2010.01624.x

12. Sun $W L$, Chen $L L$, Zhang $S Z, W u Y M$, Ren $Y Z$, Qin $G M$. Inflammatory cytokines, adiponectin, insulin resistance and metabolic control after periodontal intervention in patients with type 2 diabetes and chronic periodontitis. Intern Med. 2011; 50(15):1569-74. doi: 10.2169/internalmedicine.50.5166

13. Page RC, Offenbacher S, Schroeder HE, Seymour GJ, Kornman $\mathrm{KS}$. Advances in the pathogenesis of periodontitis: summary of developments, clinical implications and future directions. Periodontol 2000. 1997;14(1):216-48. doi: 10.1111/j.16000757.1997.tb00199.x 
14. Liljenberg B, Lindhe J, Berglundh T, Dahlén G, Jonsson R. Some microbiological, histopathological and immunohistochemical characteristics of progressive periodontal disease. J Clin Periodontol. 1994; 21(10):720-7. doi:10.1111/j.1600051X.1994.tb00793.x

15. Garlet GP, Cardoso CR, Silva TA, Ferreira BR, Avila-Campos $\mathrm{MJ}$, Cunha FQ, et al. Cytokine pattern determines the progression of experimental periodontal disease induced by Actinobacillus actinomycetemcomitans through the modulation of MMPs, RANKL, and their physiological inhibitors. Oral Microbiol Immunol. 2006;21(1):12-20. doi: 10.1111/j.1399$302 \times .2005 .00245 . x$

16. Jankovic D, Liu Z, Gause WC. Th1- and Th2-cell commitment during infectious disease: asymmetry in divergent pathways. Trends Immunol. 2001;22(8):450-7. doi: 10.1016/S14714906(01)01975-5

17. Bettelli E, Oukka M, Kuchroo VK. T(H)-17 cells in the circle of immunity and autoimmunity. Nat Immunol. 2007;8(4):345-50. doi: 10.1038/ni0407-345

18. Vernal R, Dutzan N, Chaparro A, Puente J, Antonieta Valenzuela M, Gamonal J. Levels of interleukin-17 in gingival crevicular fluid and in supernatants of cellular cultures of gingival tissue from patients with chronic periodontitis. J Clin Periodontol. 2005;32(4):383-9. doi: 10.1111/j.1600-051X.2005.00684.x

19. Oda T, Yoshie H, Yamazaki K. Porphyromonas gingivalis antigen preferentially stimulates $T$ cells to express IL-17 but not receptor activator of NF-kappaB ligand in vitro. Oral Microbiol Immunol. 2003;18(1):30-6. doi: 10.1034/j.1399-302X.2003.180105.x

20. Ribeiro FV, de Mendonça AC, Santos VR, Bastos MF, Figueiredo LC, Duarte PM. Cytokines and bone-related factors in systemically healthy patients with chronic periodontitis and patients with type 2 diabetes and chronic periodontitis. J Periodontol. 2011;82(8):1187-96. doi: 10.1902/jop.2011.100643

21. Ainamo J, Bay I. Problems and proposals for recording gingivitis and plaque. Int Dent J. 1975;25(4):229-35. doi: 10.2337/ diacare.28.suppl_1.S37

22. Górska R, Gregorek H, Kowalski J, Laskus-Perendyk A, Syczewska M, Madali冈ski K. Relationship between clinical parameters and cytokine profiles in inflamed gingival tissue and serum samples from patients with chronic periodontitis. J Clin Periodontol. 2003;30(12):1046-52. doi: 10.1046/j.0303-6979.2003.00425.x
23. Takahashi K, Azuma T, Motohira H, Kinane DF, Kitetsu S. The potential role of interleukin-17 in the immunopathology of periodontal disease. J Clin Periodontol. 2005;32(4):369-74. doi: 10.1111/j.1600-051X.2005.00676.x

24. Santos VR, Lima JA, Miranda TS, Feres M, Zimmermann GS, Nogueira-Filho $G$ da $R$, et al. Relationship between glycemic subsets and generalized chronic periodontitis in type 2 diabetic Brazilian subjects. Arch Oral Biol. 2012;57(3):293-9. doi: 10.1016/j.archoralbio.2011.08.003

25. Duarte PM, de Oliveira MC, Tambeli CH, Parada CA, Casati MZ, Nociti FH Jr. Overexpression of interleukin-1 beta and interleukin- 6 may play an important role in periodontal breakdown in type 2 diabetic patients. J Periodontal Res. 2007;42(4):377-81. doi: 10.1111/j.1600-0765.2006.00961.x

26. Goh SY, Cooper ME. Clinical review: the role of advanced glycation end products in progression and complications of diabetes. J Clin Endocrinol Metab. 2008;93(4):1143-52. doi: 10.1210/jc.2007-1817

27. Chang PC, Chien LY, Chong LY, Kuo YP, Hsiao JK. Glycated matrix up-regulates inflammatory signaling similarly to Porphyromonas gingivalis lipopolysaccharide. J Periodontal Res. 2013;48(2):18493. doi: 10.1111/j.1600-0765.2012.01519.x

28. Zizzi A, Tirabassi G, Aspriello SD, Piemontese M, Rubini C, Lucarini G. Gingival advanced glycation end-products in diabetes mellitus-associated chronic periodontitis: an immunohistochemical study. J Periodontal Res. 2013;48(3):293301. doi: 10.1111/jre.12007

29. Takeda M, Ojima M, Yoshioka H, Inaba H, Kogo M, Shizukuishi $S$, et al. Relationship of serum advanced glycation end products with deterioration of periodontitis in type 2 diabetes patients. J Periodontol. 2006;77(1):15-20. doi: 10.1902/jop.2006.77.1.15

30. Tervonen $T$, Lamminsalo $S$, Hiltunen $L$, Raunio $T$, Knuuttila $M$. Resolution of periodontal inflammation does not guarantee improved glycemic control in type 1 diabetic subjects. J Clin Periodontol. 2009;36(1):51-7. doi: 10.1111/j.1600051X.2008.01343.x

Received on: $25 / 3 / 2015$ Final version resubmitted on: 18/5/2015 Approved on: 7/8/2015 